\title{
Article
}

\section{In-utero Ramadan exposure and child nutrition}

\author{
Hoi Chu ${ }^{1}$, Srinivas Goli 2,3,* and Anu Rammohan 4,* \\ 1 Department of Economics, University of Western Australia, Perth, WA 6009, Australia; hoi.chu@uwa.edu.au \\ 2 Australia India Institute, University of Western Australia, Perth, WA 6009, Australia \\ 3 Population Studies, CSRD, Jawaharlal Nehru University, New Delhi, 110067, India \\ 4 Department of Economics, University of Western Australia, Perth, WA 6009, Australia; anu.rammo- \\ han@uwa.edu.au \\ * Correspondence: srinivas.goli@uwa.edu.au; Tel.: +61-416271232
}

\begin{abstract}
In this study, we analyse if in-utero exposure to Ramadan fasting period is negatively associated with child nutrition? The data for the analyses come from a retrospective assessment of 924,198 children from 103 demographic and health surveys (DHS) across 56 countries during the period 2003-2020. Considering the month-long Ramadan exposure as a natural experiment, we implement an intent-to-treat framework, comparing outcomes among individuals who were exposed to Ramadan at any time in-utero to those who were not exposed. Our findings do not show significant evidence to conclude that in-utero exposure to Ramadan fasting period is negatively associated with child nutrition. On the contrary, except for stunting in children who had in-utero exposure to Ramadan during the first trimester, among Muslims, we find slightly better nutritional outcomes among children exposed in-utero to Ramadan period. The better nutritional outcomes among children exposed in-utero can be attributed to high nutritious food intake and better hygienic practices during holy months of Ramadan compared to usual months. Our main results are robust to multiple robustness checks.
\end{abstract}

Keywords: Child nutrition; Religion; Ramadan fasting; In-utero exposure

\section{Introduction}

The practice of Ramadan is one of the five pillars of Islamic law, besides pilgrimage, prayers, encompassing charity, and testimony of faith. During the holy month of Ramadan in a lunar calendar, Muslims abstain from food and drinks (including water) from dawn to sunset. Despite Quran exempting pregnant and lactating women from participating in Ramadan fasting, in most cultures, they prefer to fast [1, 2]. Previous research shows that between $70 \%$ to $90 \%$ of Muslim women, including pregnant mothers, participate in fasting for some days during the Ramadan month $[3,4,5,6]$. Thus, Ramadan fasting will overlay with pregnancy in three out of four births which roughly accounts for more than 1 billion Muslims alive today who had in-utero exposure to Ramadan [7, 8].

The nutrition and dietary behaviour during the in-utero period has been critically linked to child health, physical growth, cognitive development, and future abilities [9]. Known as the 'fetal origins' hypothesis, undernutrition in the womb during the middle to late pregnancy stages has been linked to a wide range of adverse health outcomes $[9,10$, 11]. Although, metabolic penalties of fasting during Ramadan in pregnant and lactating women were observed in the mid to late 1980s [12, 13], during the last decade or so, the studies have been increasingly presenting evidence that exposure to maternal fasting during Ramadan months has implications for child development $[7,8,14]$. According to Almond and Mazumder [8], fasting during pregnancy can lead to adverse effects on maternal and fetal health.

In contrast, an influential study in the Journal of Perinatology of the Nature group by Kavehmanesh and Abolghasemi [15] studied mothers who delivered in medical cen- 
tres in Tehran and established "maternal fasting during Ramadan did not have a significant effect on the neonatal birth weight". Similarly, Petherick Tuffnell and Wright [16] studied pregnant Muslim women living in the UK who fasted during Ramadan and observed that fasting was not found to be associated with adverse birth outcomes in their sample. Other studies by Savitri et al. [17], Moradi [18], Ziaee et al. [19], and systematic reviews of literature by Oosterwijk et al. [1] and Glazier et al. [20] present a more neutral view on the relationship between in-utero exposures to Ramadan fasting and health outcomes.

However, most previous studies have not investigated the change in caloric intake and drop in dietary diversity or quality among pregnant women exposed to Ramadan fasting compared to those not. Observing the eating practices during Ramadan, it is quite possible that despite the change in the timing of consumption, there may be no change in the total caloric consumption, quality, and dietary diversity. For instance, based on a prospective cohort study among schooling Ghanaian adolescents who fasted during Ramadan, Ali and Abizari [20] reported that fasting made marked changes in typical food patterns and helped to improve dietary diversity. Similarly, the evidence from rural Bangladesh suggests that exposure to Ramadan helps to increase dietary quality in both fasting and non-fasting Muslim women [3].

Although, we do not have the information on caloric consumption, quality, and dietary diversity from uniformly designed and linkable surveys across the low and lowermiddle-income countries to assess the effect of Ramadan fasting on food intake; it is possible to test the validity of the hypothesis "prenatal exposure to Ramadan leads to poor child development" across a large number of countries of diverse regions, cultures, and food practices over the time. Moreover, to the best of our knowledge the evidence surfaced about the association between in-utero exposure to Ramadan and child development are from single-country studies representing specific geographies and cultures with relatively small samples. Thus, there is a need to re-assess this relationship to see whether the hypothesis "in-utero exposure to Ramadan fasting month detrimental for child nutritional status" holds in case of wider geographical and cultural context or not?

Against this backdrop, our paper aims to analyse the links between in-utero exposure to Ramadan fasting and child nutritional outcomes using data from a sample of 924,198 children from the 103 Demographic Health Surveys (DHS) conducted over the period 2003-2020 from 56 countries. Our paper contributes to the existing knowledge on the links between in-utero exposure to Ramadan fasting and child health or development outcomes in several ways. First, previous studies on the links between Ramadan fasting and child health and development outcomes were based on single-country studies which foster diverse conclusions from different geographical and cultural contexts. Our study on the other hand examines the association between in-utero exposure to Ramadan for a large cohort of children focusing on anthropometric outcomes of children aged under five years from diverse geographies, cultures, and over time. Since there is no information in our dataset on whether a mother fasted, following previous studies [10, 14], we adopt an intent-to-treat framework comparing outcomes among individuals who were exposed to Ramadan at any time in-utero (the treatment group) to those who were not exposed (the control group). Second, we adopt multiple robustness checks to verify the main findings. Third, investigation of heterogeneity of the relationship between in-utero exposure to Ramadan and child nutritional outcomes by different stages of pregnancy from a relatively large sample also adds to the existing knowledge.

Our findings suggest no clear association between in-utero exposure to Ramadan fasting period and child nutritional outcomes. At an outset, in-utero exposure to Ramadan shows a negative association with child nutrition, especially with children underweight. However, this relationship varies across the stages of pregnancy showing a positive relationship when exposure to Ramadan is at the early stages of pregnancy; while turning into a negative relationship for later stages of pregnancy. Overall, there is no robust evidence to say that in-utero exposure to Ramadan shows a negative impact on child anthropometrics. 
The paper is organised into six sections: the first section presents the introduction, second and third provide a review of literature and data and methods. Section four presents the empirical strategy used in the paper. While, sections five and six present results, discussion, and conclusion respectively.

\section{Literature Review}

We can classify the existing literature that tested the hypothesis of ' in-utero exposures to Ramadan on poor child development' into two categories: (1) those support the hypothesis, (2) while others do not support the hypothesis or failed to present sufficient evidence to support the hypothesis. Previous research [6, 22] performed early investigations that recognized the relationship between in-utero exposure to Ramadan fasting month and thinner and shorter body sizes later in life. The developmental origins of health and disease (DOHaD) theory have been used to explain the relationship between 'in-utero exposure to Ramadan' and child development [23]. Maternal diet is assumed to drive the baby's growth, a phenomenon identified as 'fetal programming' [9]. Later, Almond and Madzumer [8] show that exposure to Ramadan may lead to low birth weight among Arab children in Michigan, and higher disability in Uganda and Iraq. In their subsequent work, Almond, Mazumder, and Ewijk [24] showed detrimental effects of in-utero Ramadan exposure on children's academic performance. Chaudhry and Mir's study from Pakistan finds that prenatal exposure to Ramadan is associated with higher stunting and underweight among children [14]; whereas in an Indonesia context, Kunto and Mandemakers [5], Majid [7], and Van Ewijk et al. [6] showed that fasting exposure led to smaller stature in adolescence, lower cognitive ability later in life, and thinner stature among Muslim people aged 18 or older, respectively. In the case of Burkina Faso, in-utero exposure to fasting during Ramadan was associated with higher child mortality [25].

On the other hand, Petherick Tuffnell and Wright [16] and Kavehmanesh and Abolghasemi [15] studied mothers from Tehran and the United Kingdom and present the evidence that Ramadan fasting does not have a significant effect on neonatal health and birth weight. Similarly, Awwad et al. [26], using a prospective study design demonstrate that Ramadan fasting failed to upturn the risk of preterm delivery in pregnant women irrespective of the gestational age. Whereas the investigation by Savitri et al. [17], Glazier et al. [20], Moradi [18], and Ziaee et al. [19] present a more neutral view on the relationship between in-utero exposure to Ramadan fasting and health outcomes. For instance, Moradi [18] investigated pregnant women of fasting and non-fasting groups during the month of Ramadan in Iran, author estimated growth parameters including fetal weight, amniotic fluid, and Doppler indices of uterine and umbilical arteries. The results showed no statistical difference in these parameters between fasting and non-fasting groups. Ziaee et al. [19] studied a sample of 189 pregnant women who delivered in a hospital in Tehran in 2004 and found that there was no significant difference in weight, height, and head circumference of infants of mothers in fasting or non-fasting groups. Nikoo et al. [27] also informed no detrimental effect of Ramadan fasting on fetal physical and mental growth. Savitri et al.'s [17] study in the case of the Netherlands also found that there was no significant association between in-utero exposure to Ramadan and birth weight, gestational length, perinatal mortality, low Apgar, or mild congenital anomalies. Savitri et al. [28] also found no difference in birth weight between those who were exposed and not exposed inutero to Ramadan in the context of Jakarta, Indonesia.

Glazier et al. [20] conduct a meta-analysis relying on 22 published studies and found that there were no adverse effects of Ramadan fasting on birth weight and preterm delivery. They also report that there is insufficient evidence regarding the potential effects of exposure to Ramadan fasting on other perinatal outcomes. Most recently, Oosterwijk et al. [1] systematically review 43 studies and conclude that there is no strong evidence to support the hypothesis that there are negative effects of exposure to Ramadan fasting on children's health outcomes. Both these systematic reviews and Meta-analyses studies which also assessed the quality of existing studies suggest a need to conduct studies with 
a robust design to investigate the association of Ramadan fasting and adverse maternal and child health outcomes.

Overall, the review of previous literature suggests an inconclusive picture of the relationship between Ramadan fasting and child health, especially their nutrition. However, a significant gap noticed in the previous empirical studies is that they represent a specific geographic cultural context of Islamic food and lifestyle practices during Ramadan. Therefore, they do not represent a holistic view of a global or regional context. Through this study, we attempt to fill this gap.

\section{Materials and Methods}

Our study uses data from the Demographic and Health Surveys (DHS), a collection of nationally-representative repeated cross-sectional surveys conducted in over 90 developing countries since 1984. The DHS interviewed women of childbearing age (15 to 49 years) using a standard questionnaire across all countries and included detailed questions on the socio-economic and demographic characteristics of female respondents and their households, including information on education, marital status, and religion. For the purposes of our study, we used information collected from the detailed birth history of all children born in the five years before the survey, and anthropometric measures for these children. Our final sample consists of more than 924,000 observations of children aged 05 years from 103 surveys conducted over the period 2003-2020 in 56 countries.

\subsection{Selection of sample for analysis}

Figure 1 presents the detailed sample selection procedure of the study. Our initial dataset consists of 110 surveys conducted in 62 countries that provide information on child stunting and underweight. However, 22 out of 62 countries provide no information about religious composition. Considering the religious composition of the general population, we imputed 12 countries as 100\% non-Muslim: Armenia, Bolivia, Colombia, Dominican Republic, Guatemala, Honduras, Haiti, Peru, Myanmar, Namibia, Papua New Guinea, and South Africa; while 7 countries as 100\% Muslim: Jordan, Maldives, Niger, Pakistan, Tajikistan, Turkey, and Yemen. Nevertheless, we exclude 6 countries out of these 7 countries because Turkey and Colombia have no information on media access; Yemen has no information on mothers' education; Kenya, Tanzania, and Eswatini provide no information of religion and could not be imputed. One survey in Madagascar (2009) provided only information on stunting, not underweight.

To identify the child's potential in-utero exposure to Ramadan fasting period, we collect data on the occurrence of Ramadan from several sources. First, we collect the information through Umm al-Qura Calendar which is a civil Islamic calendrical system used in Saudi Arabia (Umm al-Qura Calendar converter to convert any date (1951-2100) from Gregorian to Hijri can be found from several online sources, such as: https://webspace.science.uu.nl/ gent0113/islam/ummalqura_converter.htm). Then we corroborate the records using online sources to make sure of their accuracy. This data is linked with DHS data to identify whether a child had in-utero exposure to the Ramadan month or not.

\subsection{Dependent variables}

Our dependent variables include the two standard indices of physical growth that describe child nutrition included in this analysis are height-for-age (stunting) and weightfor-age (underweight). DHS includes anthropometric components in which all children under 5 years of age were measured and expressed as Z-scores in standard deviations from the mean of the reference population, calculated using WHO's current Child Growth Standards reference population median and standard deviation [29]. 


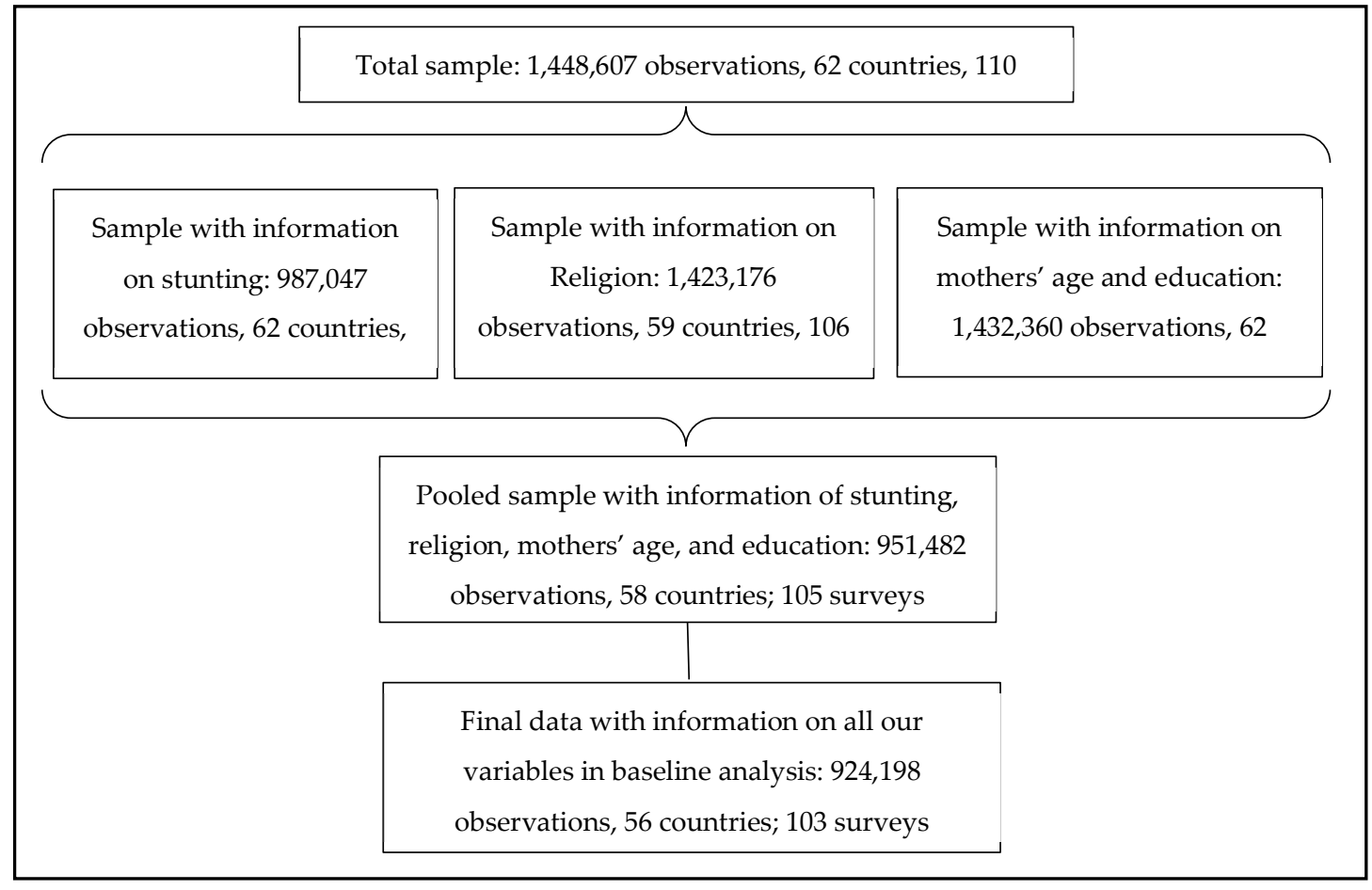

Figure 1. Sample selection procedure in the study

The height-for-age Z-score (HAZ) measures the child's linear growth according to age. Children with low height-for-age are said to be stunted. This indicator reflects the cumulative effects of growth deficiency and is used to measure long-term nutrition. It is associated with a number of factors including chronic insufficient food intake, frequent infections, sustained incorrect feeding practices, and low socio-economic family status [30].

The weight-for-age z-score (WAZ) measures the child's weight, again in standard deviations from the mean of the reference population. Children with low weight for age are said to be underweight. This indicator has been used to monitor the growth of children and is typically regarded as a measure of short-term nutrition. Socio-economic and environmental factors play a role in explaining departures from optimal growth [31, 32].

\subsection{Explanatory variables}

The key explanatory variable in this study is a measure of in-utero exposure to the Ramadan fasting period, defined as a binary variable, taking on a value of 1 if a child is exposed, and a value of 0 if otherwise. To assign a child's in-utero exposure to the Ramadan fasting period, we use the information on the month and year of birth of the child. To construct the exposure variable, assuming that the pregnancy period is 9 months before the month of birth, we assign a value of 1 if the child was exposed to the Ramadan fasting period. Since the Ramadan month may overlap two months (i.e. start in one month and ends in the next month) in a Gregorian calendar year, we define starting and ending the month of the Ramadan month ${ }^{1}$. A child will be considered as not being exposed in-utero

\footnotetext{
1 A starting or ending month of Ramadan month has at least 7 days overlapping with the Ramadan month. For example, Ramadan month in 2016 was from 6 of June to 6 of July, then June (but not July) is counted as ending month. A child born in May 2017 for instance, the imputed pregnancy
} 
to the Ramadan month if the starting month of pregnancy occurred after the ending Ramadan month of last year and the last month of pregnancy period occurred before the starting Ramadan month in the current year; otherwise the child will be considered as exposed.

Here, two points are worth noting. Firstly, as pointed out earlier, even though pregnant Muslim women do not need to fast during Ramadan month, about $70 \%$ to $90 \%$ of Muslim women (including pregnant mothers), participate in fasting during Ramadan month $[3,4,5,6]$. However, there is no information in our dataset on whether a mother fasted. Therefore, as previously mentioned, in keeping with previous studies such as Chaudhry \& Mir [14], we adopt an intent-to-treat framework comparing outcomes among individuals who were exposed to Ramadan at any time in-utero (the treatment group) to those who were not exposed (the control group). Given the imperfect information about the date of birth of children, we acknowledge that some children may incorrectly be classified as being in the exposure group when they should be in the non-exposure group, and vice versa.

Secondly, data on the exact date of birth of the child is available only in surveys conducted recently, referred to as DHS-7 [including: Albania (2017), Armenia (2015), Angola (2015), Bangladesh (2017), Benin (2017), Burundi (2016), Cameroon (2018), Ethiopia (2008), Gambia (2019), Ginea (2018), Haiti (2016), Liberia (2019), Mali (2018), Myanmar (2015), Maldives (2015), Malawi (2015), Nigeria (2018), Nepal (2016), Papua New Ginea (2016), Pakistan (2017), Sierra Leon (2019), Senegal (2017, 2018, 2019), Taijikistan (2017), Timo Leste (2016), Uganda (2016), South Africa (2016), Zambia (2018), and Zimbabwe (2015)]. To test the robustness of our results, we conduct a sub-sample analysis for the group of children in these datasets. This includes a sample of around 163,000 children from 28 countries. In this case, following Majid [7] and Almond and Mazumder [8], we assume that the pregnancy period lasts for an average of 266 days before the birth date. Furthermore, a child is considered to be exposed to fasting in-utero if the Ramadan month overlaps the gestation period by at least 7 days.

Third, although Ramadan month potentially applies only to Muslim children, nonMuslims are reported to have spillover effects through market, governance, and working timings, especially in Muslim majority countries [3, 5, 33]. Thus, first, we code two binary variables indicating whether a child's mother is Muslim (1) or not (0), and Exposure: yes (1) and no (0), second, we run interaction between them for regression models. In our sample, Muslims account for $32.4 \%$ of observations, and by our method of construction $82.8 \%$ of Muslim children are expected to have been exposed to fasting in-utero during Ramadan. Figure 2 below shows the distribution of stunted and underweight children by religion and exposure status drawn from our full sample. Overall, Muslim children are less likely to be stunted and underweight compared to non-Muslim children. However, within Muslim children, we see some small differences in stunting and underweight by exposure status where children with in-utero exposure to Ramadan show better outcomes than non-exposure children.

period was Aug. 2016-Apr. 2017; Ramadan month in 2016 was 6 Jun. - 6 Jul. and in 2017 was 27 May - 25 Jun.; thus, this child was not exposed inutero to the Ramadan fasting month. If the child was born in January 2017, the pregnancy period would overlap the Ramadan month in 2016. 


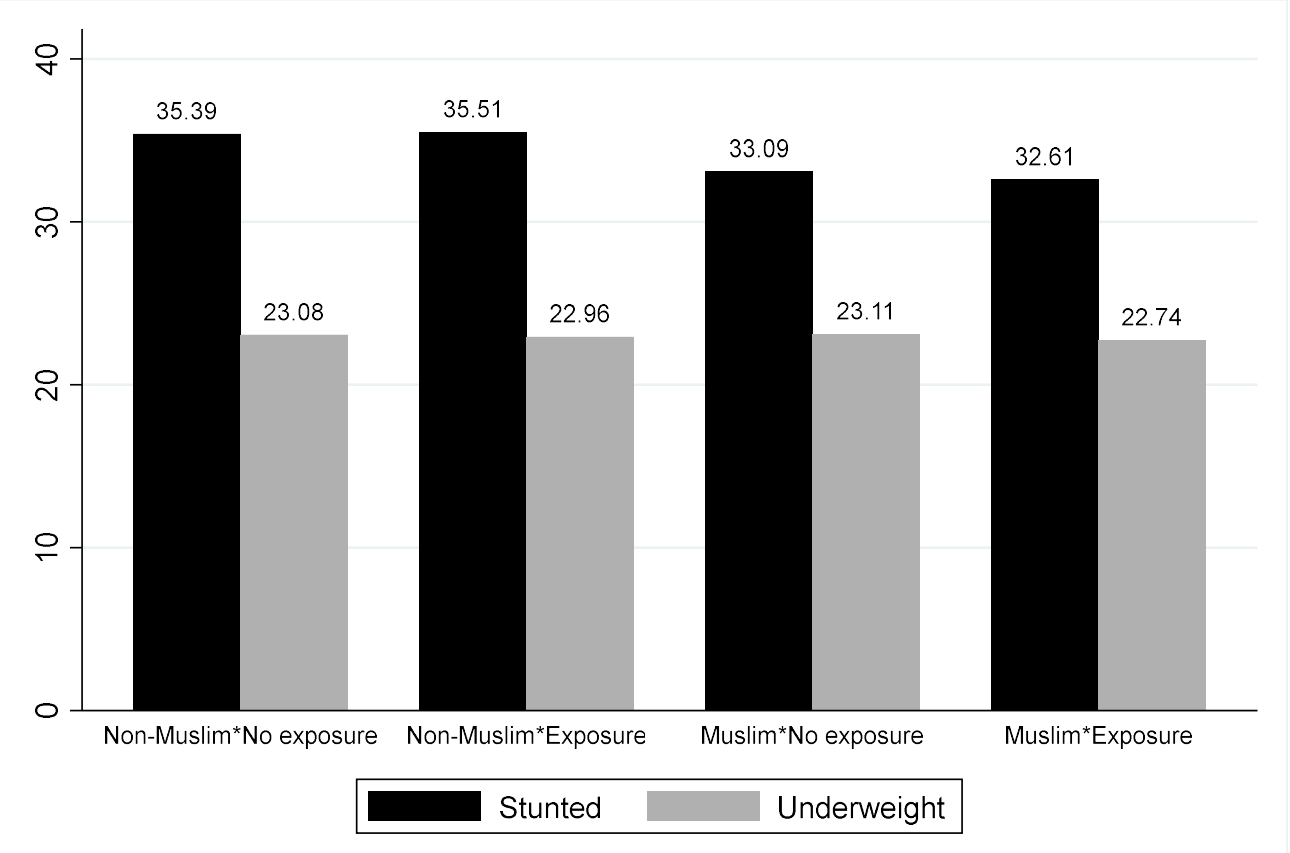

Figure 2. Distribution of stunted and underweight children (\%) by Ramadan exposure status

\subsection{Other control variables}

Additionally, we control for an array of child and household socio-economic and demographic characteristics. These include the gender and birth order of the child, whether the child is a part of single or multiple births; mothers' education, age, media accessibility. Household characteristics such as rural or urban residence, sex, age of the household head, household size. To account for a household's economic status, we use data on the wealth index available in the dataset, where households are divided into five wealth quintiles ranging from poorest to richest households. Table 1 presents the descriptive statistics of all the variables that are included in our empirical analysis.

\section{Empirical Analysis}

We empirically estimate the association between in-utero exposure to the potential Ramadan fasting period and two key child anthropometric measures. Given the binary nature of both our outcome variables Stunting (HAZ) and Underweight (WAZ), we estimate a Probit estimation model. Specifically, we estimate the following equation:

$\operatorname{Probit}\left\{P\left(Y_{j, c, t}=1\right) \mid\right.$ control $\}=\beta_{0}+\beta_{1}$ Muslim $_{j, c, t}+\beta_{2}$ Exposure $_{j, c, t}+\beta_{3}$ Muslim $_{j, c, t} *$ Exposure $_{j, c, t}+\beta_{j} X_{j, c, t}+\theta_{c}+\mu_{t}+\varepsilon_{j, c, t}$

Where, $Y j, c, y$ is a binary variable indicating that a child $\mathrm{j}$ in country $\mathrm{c}$ and year $\mathrm{t}$ is stunted or underweight. Muslim is a dummy variable, taking the value of 1 if the child's mother is Muslim, 0 otherwise; Exposure is a binary variable showing whether a child is exposed to the Ramadan month in-utero. $X$ is a vector of control variables characterising the children, their mother, and household. We control for country fixed-effects by adding the parameter $\theta \_c$ and year fixed-effects by adding the parameter $\mu_{-} t$.

After running Probit regression of equation (1) above, we then implement estimation of marginal effects that show the relative change in probability of being stunted or underweight of children with particular characteristics compared to a base group. In equation 
(1) above, with regard to exposure in-utero of Ramadan, the base group is non-Muslim children whose mothers were not exposed to the fasting month while in pregnancy. Also, since we control for country fixed effects $\left(\theta_{-} c\right)$, the results are to compare children by the status of exposure within a country. The signs and significance of coefficients $\beta 1, \beta 2$, and $\beta 3$ will let us know the relative difference in probability of a child being stunted/underweight compared to the base group - non-Muslim non-exposure children.

\section{Results}

\subsection{Descriptive Statistics}

Table 1 provides descriptive statistics of the main variables used in the empirical analysis. Of the total sample, approximately $51 \%$ of the children are male, and nearly all the children are part of a single birth $(>97 \%)$. Regarding mother's characteristics, there is a big difference in education between non-Muslim mothers and Muslim counterparts. Around $49.5 \%$ of Muslim mother has no education, compared to only around $25.5 \%$ in the non-Muslim population. Characteristic of household is also observed, including sex and age of household head, showing the dominance of male ( $>82 \%$ within the non-Muslim population) taking on the role of household head ( $>85 \%$ within Muslim communities). Also, slightly more non-Muslim households (67.6\%) live in the rural area than Muslim households (around 67\%); Muslim household size is on average larger than non-Muslim households: proportion of households having 6 persons or more is around $66 \%$ in Muslim communities, compared to $55 \%$ in the non-Muslim population. Lastly, there are no significant differences in the distribution of the population by wealth index between non-Muslim and Muslim populations. 
Table 1. Descriptive Statistics of variables

\begin{tabular}{|c|c|c|c|}
\hline Variables & Non-Muslim (\%) & $\begin{array}{c}\text { Muslim \& Non-exposure } \\
(\%) \\
\end{array}$ & $\begin{array}{c}\text { Muslim \& exposure } \\
(\%)\end{array}$ \\
\hline \multicolumn{4}{|c|}{ Dependent Variable } \\
\hline Child is stunted & $35.49(0.06)$ & $33.09(0.15)$ & $32.61(0.07)$ \\
\hline Child is underweight & $22.98(0.05)$ & $23.11(0.13)$ & $22.74(0.06)$ \\
\hline \multicolumn{4}{|c|}{ Explanatory variables } \\
\hline Child is male & $51.05(0.06)$ & $51.05(.015)$ & $50.84(0.07)$ \\
\hline Child is a part of a single birth & $97.87(0.02)$ & $97.37(0.04)$ & $97.44(0.02)$ \\
\hline Bird order of child: 1 st & $30.18(0.06)$ & $24.76(0.14)$ & $24.24(0.06)$ \\
\hline Bird order of child: 2 nd & $25.73(0.06)$ & $21.7(0.13)$ & $21.84(0.06)$ \\
\hline Bird order of child: 3rd+ & $44.08(0.06)$ & $53.54(0.15)$ & $53.92(0.07)$ \\
\hline Mother has no education & $25.47(0.06)$ & $49.12(0.13)$ & $49.75(0.06)$ \\
\hline Mother has primary education & $30.85(0.06)$ & $17.21(0.14)$ & $17.8(0.07)$ \\
\hline Mother has secondary or higher & $43.68(0.06)$ & $33.67(0.15)$ & $32.45(0.07)$ \\
\hline Mother's age: $15-19$ & $4.85(0.03)$ & $5.46(0.07)$ & $5.35(0.03)$ \\
\hline Mother's age: $20-29$ & $58.07(0.06)$ & $53.92(0.15)$ & $53.99(0.07)$ \\
\hline Mother's age: $30+$ & $37.08(0.06)$ & $40.62(0.15)$ & $40.65(0.07)$ \\
\hline Household head is male & $82.36(0.05)$ & $86.23(0.12)$ & $85.87(0.05)$ \\
\hline Age of household head: 13-29 & $20.29(0.05)$ & $13.3(0.12)$ & $13.52(0.06)$ \\
\hline \multicolumn{4}{|c|}{ Table 1. Cont. } \\
\hline Age of household head: 30-59 & $65.19(0.06)$ & $69.67(0.15)$ & $68.97(0.07)$ \\
\hline Age of household head: $60+$ & $14.52(0.05)$ & $17.03(0.11)$ & $17.52(0.05)$ \\
\hline Household size: 1-3 persons & $9.52(0.03)$ & $6.54(0.07)$ & $6.69(0.04)$ \\
\hline Household size: 4-5 persons & $35.74(0.06)$ & $27.58(0.15)$ & $27.09(0.07)$ \\
\hline Household size: $6+$ persons & $54.74(0.06)$ & $65.88(0.15)$ & $66.22(0.07)$ \\
\hline Access to media & $76.28(0.05)$ & $73.98(0.13)$ & $74.4(0.06)$ \\
\hline Household is in rural area & $67.64(0.06)$ & $67.43(0.14)$ & $66.84(0.07)$ \\
\hline Wealth Index: 1st quintile & $23.44(0.06)$ & $23.44(0.13)$ & $23.21(0.06)$ \\
\hline Wealth Index: 2nd quintile & $21.78(0.05)$ & $22.01(0.13)$ & $21.74(0.06)$ \\
\hline Wealth Index: 3rd quintile & $20.29(0.05)$ & $20.11(0.12)$ & $20.44(0.06)$ \\
\hline Wealth Index: 4th quintile & $18.6(0.05)$ & $19.04(0.12)$ & $19.16(0.05)$ \\
\hline Wealth Index: 5th quintile & $15.88(0.05)$ & $15.41(0.11)$ & $15.44(0.05)$ \\
\hline No. of observations & 624,902 & 51,461 & 247,835 \\
\hline
\end{tabular}

\subsection{Regression Results}

The main results of the empirical analysis are presented in Tables 2 and 3, providing estimates of marginal effects with stunting and underweight being the binary outcome variables, respectively.

5.2.1. In-utero exposure to Ramadan fasting period and child stunting

Across all our models in Table 2, we found that relative to a non-Muslim child (nonexposed), a child from the Muslim religion had a higher probability of being stunted. The variable in-utero exposure to Ramadan shows a statistically significant positive association 
with child stunting. Interestingly, the interaction term is negative and statistically significant in all regressions. In the full sample (Table 2, column 1) this indicates that compared to Muslim (non-exposed) children, a Muslim child who is exposed to Ramadan fasting inutero has a $0.5(=0.003-0.008)$ percentage point lower probability of being stunted. This suggests that in-utero exposure to Ramadan fasting is not associated with higher child stunting. We see that this finding is robust for different sample settings, such as samples: excluding American countries (column 2): only African countries (column 3); excluding India (column 4).

In column 5, we used a sample of recent DHS surveys in which the information of date of birth (rather month of birth) is used to measure exposure to Ramadan. The finding remains unchanged, that is Muslim children who had in-utero exposure to Ramadan are roughly $0.7(=0.007-0.014)$ percentage points less likely to be stunted.

\subsubsection{Ramadan fasting exposure and child stunting}

Our results for children underweight are presented in Table 3 and are consistent with our findings for stunting. In other words, the probability of being underweight is higher among Muslim children compared to non-Muslim ones. However, among Muslim children, exposure to Ramadan fasting in-utero is negatively associated with being underweight. Specifically, in the full sample results (column 1), the estimates corresponding to the category with exposure to Ramadan (Exposure) are positive but not significant. This supports our prior estimation expectation that exposure is not an issue for non-Muslim children. Whereas the coefficient of interaction (Exposure to Ramadan *Muslim) is negative and significant in all regressions. Hence, relative to non-exposed Muslim children, a Muslim child exposed to Ramadan fasting in utero has a $0.3(=0.002-0.005)$ percentage point lower probability of being underweight. The difference in the sample of DHS7 is 1.0 percentage points lower in favor of exposed Muslim children $(=0.001-0.011)$. Hence, from both regressions of stunting and underweight, it is evident that exposure to the Ramadan in-utero does not have negative effects on child health. 
Table 2. Exposure to Ramadan fasting period on child stunting

\begin{tabular}{|c|c|c|c|c|c|}
\hline & $\begin{array}{c}(1) \\
\text { Global }\end{array}$ & $\begin{array}{c}(2) \\
\text { Excl. Americas }\end{array}$ & $\begin{array}{c}(3) \\
\text { Africa }\end{array}$ & $\begin{array}{c}(4) \\
\text { Excl. India }\end{array}$ & $\begin{array}{c}(5) \\
\text { DHS-7 }\end{array}$ \\
\hline Muslim & $0.025^{* * *}(0.003)$ & $0.027^{* * *}(0.003)$ & $0.047^{* * * *}(0.004)$ & $0.035^{* * *}(0.004)$ & $0.033^{* * *}(0.006)$ \\
\hline Exposure & $0.003^{* *}(0.002)$ & $0.005^{* * *}(0.002)$ & $0.011^{* * *}(0.002)$ & $0.006^{* * *}(0.002)$ & $0.007^{* *}(0.004)$ \\
\hline Muslim* Exposure & $-0.008^{* * * *}(0.003)$ & $-0.009^{* * *}(0.003)$ & $-0.014^{* * *}(0.004)$ & $-0.008^{* * * *}(0.003)$ & $-0.014^{* *}(0.006)$ \\
\hline Child is male & $0.035^{* * *}(0.001)$ & $0.035^{* * *}(0.001)$ & $0.048^{* * *}(0.001)$ & $0.041^{* * *}(0.001)$ & $0.041^{* * *}(0.002)$ \\
\hline Child's age (months) & $0.018^{* * *}(0.000)$ & $0.018^{* * *}(0.000)$ & $0.019^{* * *}(0.000)$ & $0.018^{* * *}(0.000)$ & $0.017^{* * *}(0.000)$ \\
\hline Child's age (months) squared & $-0.000^{* * * *}(0.000)$ & $-0.000^{* * *}(0.000)$ & $-0.000^{* * *}(0.000)$ & $-0.000^{* * * *}(0.000)$ & $-0.000^{* * *}(0.000)$ \\
\hline \multicolumn{6}{|l|}{ Child's birth order: $1^{\text {st }}$ birth (ref.) } \\
\hline Child's birth order: $2^{\text {nd }}$ birth & $0.015^{* * *}(0.001)$ & $0.013^{* * *}(0.001)$ & $-0.001(0.002)$ & $0.009^{* * *}(0.002)$ & $0.005(0.003)$ \\
\hline Child's birth order: $3^{\text {rd }}$ birth & $0.037^{* * * *}(0.002)$ & $0.031^{* * *}(0.002)$ & $0.012^{* * *}(0.002)$ & $0.029^{* * *}(0.002)$ & $0.014^{* * *}(0.004)$ \\
\hline \multicolumn{6}{|l|}{ Child is a part of a multiple birth (ref.) } \\
\hline Child is a part of a single birth & $-0.133^{* * * *}(0.004)$ & $-0.136^{* * *}(0.004)$ & $-0.159^{* * *}(0.005)$ & $-0.141^{* * *}(0.004)$ & $-0.163^{* * *}(0.008)$ \\
\hline \multicolumn{6}{|l|}{ Mother's education: no education (ref) } \\
\hline Primary education & $-0.023^{* * * *}(0.002)$ & $-0.030^{* * *}(0.002)$ & $-0.027^{* * *}(0.002)$ & $-0.022^{* * * *}(0.002)$ & $-0.034^{* * *}(0.003)$ \\
\hline Secondary education + & $-0.085^{* * *}(0.002)$ & $-0.082^{* * *}(0.002)$ & $-0.077^{* * *}(0.003)$ & $-0.086^{* * *}(0.002)$ & $-0.078^{* * *}(0.004)$ \\
\hline \multicolumn{6}{|l|}{ Mother's age: 15-19 (ref.) } \\
\hline Mother's age: $20-29$ & $-0.049^{* * *}(0.002)$ & $-0.050^{* * *}(0.003)$ & $-0.046^{* * *}(0.003)$ & $-0.048^{* * *}(0.003)$ & $-0.049^{* * *}(0.005)$ \\
\hline Mother's age: $30+$ & $-0.078^{* * *}(0.003)$ & $-0.079^{* * *}(0.003)$ & $-0.074^{* * *}(0.004)$ & $-0.075^{* * *}(0.003)$ & $-0.078^{* * *}(0.006)$ \\
\hline \multicolumn{6}{|l|}{ Household size: $6+$ persons (ref.) } \\
\hline Size: $1-3$ persons & $-0.027^{* * *}(0.002)$ & $-0.017^{* * *}(0.002)$ & $-0.007^{* *}(0.003)$ & $-0.024^{* * *}(0.002)$ & $-0.020^{* * *}(0.005)$ \\
\hline Size: $4-5$ persons & $-0.020^{* * *}(0.001)$ & $-0.015^{* * *}(0.001)$ & $-0.008^{* * *}(0.002)$ & $-0.017^{* * *}(0.001)$ & $-0.018^{* * *}(0.003)$ \\
\hline Household head is male & $0.002(0.001)$ & $0.002(0.002)$ & $0.006^{* * *}(0.002)$ & $0.004^{* * *}(0.002)$ & $0.007^{* *}(0.003)$ \\
\hline \multicolumn{6}{|l|}{ Household head's age: 13-29 (ref.) } \\
\hline Household head's age: 30-59 & $-0.020^{* * *}(0.002)$ & $-0.019^{* * *}(0.002)$ & $-0.012^{* * *}(0.002)$ & $-0.017^{* * *}(0.002)$ & $-0.015^{* * *}(0.004)$ \\
\hline Household head's age: $60+$ & $-0.027^{* * *}(0.002)$ & $-0.025^{* * *}(0.002)$ & $-0.011^{* * *}(0.003)$ & $-0.022^{* * *}(0.002)$ & $-0.015^{* * *}(0.005)$ \\
\hline $\begin{array}{l}\text { Exposed to media (TV, newspaper, } \\
\text { radio) }\end{array}$ & $-0.017^{* * *}(0.001)$ & $-0.023^{* * *}(0.001)$ & $-0.020^{* * *}(0.002)$ & $-0.014^{* * *}(0.002)$ & $-0.019^{* * *}(0.003)$ \\
\hline Rural household & $0.011^{* * *}(0.002)$ & $0.003^{* *}(0.002)$ & $0.018^{* * *}(0.003)$ & $0.021^{* * *}(0.002)$ & $0.003(0.004)$ \\
\hline \multicolumn{6}{|l|}{ Household wealth quintile: Poorest (ref.) } \\
\hline Poorer & $-0.039^{* * *}(0.002)$ & $-0.029^{* * *}(0.002)$ & $-0.021^{* * *}(0.002)$ & $-0.037^{* * * *}(0.002)$ & $-0.027^{* * * *}(0.004)$ \\
\hline Middle & $-0.078^{* * *}(0.002)$ & $-0.064^{* * *}(0.002)$ & $-0.049^{* * *}(0.002)$ & $-0.074^{* * *}(0.002)$ & $-0.065^{* * *}(0.004)$ \\
\hline Richer & $-0.116^{* * * *}(0.002)$ & $-0.103^{* * *}(0.002)$ & $-0.081^{* * *}(0.003)$ & $-0.106^{* * *}(0.002)$ & $-0.102^{* * *}(0.004)$ \\
\hline Richest & $-0.183^{* * * *}(0.002)$ & $-0.175^{* * *}(0.003)$ & $-0.151^{* * *}(0.004)$ & $-0.167^{* * *}(0.003)$ & $-0.171^{* * *}(0.005)$ \\
\hline Country dummies & Yes & Yes & Yes & Yes & Yes \\
\hline Survey year dummies & Yes & Yes & Yes & Yes & Yes \\
\hline$N$ & 924198 & 815435 & 437196 & 657891 & 163469 \\
\hline
\end{tabular}

Notes: The Table reports marginal effects with standard errors in parentheses. ${ }^{* * *},{ }^{* *}$ and ${ }^{*}$ report statistical significance at $1 \%, 5 \%$ and $10 \%$, respectively. The first column reports full sample results; South American countries excluded in column 2; Column 3 reports estimates for African countries; Column 4 excludes India, and Column 5 limits the sample to recent surveys (referred to as DHS-7). 
Table 3. Exposure to Ramadan fasting period on child underweight

\begin{tabular}{|c|c|c|c|c|c|}
\hline & (1) & (2) & (3) & (4) & (6) \\
\hline & Global & Excl. Americas & Africa & Excl. India & DHS7 \\
\hline Muslim & $0.021^{* * *}(0.003)$ & $0.023^{* * *}(0.003)$ & $0.052^{* * *}(0.003)$ & $0.044^{* * *}(0.003)$ & $0.034^{* * *}(0.005)$ \\
\hline Exposure & $0.002(0.001)$ & $0.002(0.002)$ & $0.004^{* *}(0.002)$ & $0.003^{*}(0.002)$ & $0.001(0.003)$ \\
\hline Muslim* Exposure & $-0.005^{* *}(0.002)$ & $-0.006^{* *}(0.003)$ & $-0.008^{* * *}(0.003)$ & $-0.006^{* * *}(0.002)$ & $-0.011^{* *}(0.005)$ \\
\hline Child is male & $0.018^{* * *}(0.001)$ & $0.019^{* * *}(0.001)$ & $0.027^{* * * *}(0.001)$ & $0.020^{* * *}(0.001)$ & $0.020^{* * *}(0.002)$ \\
\hline Child's age & $0.006^{* * *}(0.000)$ & $0.006^{* * *}(0.000)$ & $0.006^{* * *}(0.000)$ & $0.005^{* * *}(0.000)$ & $0.005^{* * *}(0.000)$ \\
\hline Child's age squared & $-0.000^{* * *}(0.000)$ & $-0.000^{* * *}(0.000)$ & $-0.000^{* * * *}(0.000)$ & $-0.000^{* * *}(0.000)$ & $-0.000^{* * * *}(0.000)$ \\
\hline \multicolumn{6}{|l|}{ Child's birth order: $1^{\text {st }}$ birth (ref.) } \\
\hline Child's birth order: $2^{\text {nd }}$ birth & $0.007^{* * *}(0.001)$ & $0.008^{* * *}(0.001)$ & $-0.001(0.002)$ & $0.001(0.001)$ & $0.002(0.003)$ \\
\hline Child's birth order: $3^{\text {rd }}$ birth & $0.019^{* * *}(0.001)$ & $0.019^{* * *}(0.001)$ & $0.004^{* *}(0.002)$ & $0.011^{* * *}(0.002)$ & $0.007^{* *}(0.003)$ \\
\hline \multicolumn{6}{|l|}{ Child is a part of a multiple birth (ref.) } \\
\hline Child is a part of a single birth & $-0.117^{* * *}(0.003)$ & $-0.123^{* * * *}(0.003)$ & $-0.120^{* * * *}(0.004)$ & $-0.108^{* * *}(0.003)$ & $-0.120^{* * *}(0.006)$ \\
\hline \multicolumn{6}{|l|}{ Mother's education: no education (ref) } \\
\hline Primary education & $-0.033^{* * *}(0.001)$ & $-0.036^{* * *}(0.001)$ & $-0.033^{* * * *}(0.002)$ & $-0.029^{* * *}(0.001)$ & $-0.029^{* * * *}(0.003)$ \\
\hline Secondary education + & $-0.069^{* * *}(0.001)$ & $-0.074^{* * *}(0.002)$ & $-0.062^{* * * *}(0.002)$ & $-0.062^{* * *}(0.002)$ & $-0.053^{* * * *}(0.003)$ \\
\hline \multicolumn{6}{|l|}{ Mother's age: 15-19 (ref.) } \\
\hline Mother's age: $20-29$ & $-0.031^{* * *}(0.002)$ & $-0.035^{* * *}(0.002)$ & $-0.030^{* * *}(0.003)$ & $-0.027^{* * *}(0.002)$ & $-0.026^{* * *}(0.004)$ \\
\hline Mother's age: $30+$ & $-0.050^{* * *}(0.002)$ & $-0.056^{* * * *}(0.003)$ & $-0.041^{* * *}(0.003)$ & $-0.036^{* * *}(0.002)$ & $-0.036^{* * * *}(0.005)$ \\
\hline \multicolumn{6}{|l|}{ Household size: $6+$ persons (ref.) } \\
\hline Size: 1-3 persons & $-0.014^{* * *}(0.002)$ & $-0.013^{* * *}(0.002)$ & $-0.006^{* *}(0.003)$ & $-0.009^{* * *}(0.002)$ & $-0.013^{* * * *}(0.004)$ \\
\hline Size: $4-5$ persons & $-0.013^{* * *}(0.001)$ & $-0.013^{* * *}(0.001)$ & $-0.008^{* * *}(0.002)$ & $-0.010^{* * *}(0.001)$ & $-0.014^{* * * *}(0.002)$ \\
\hline Household head is male & $0.001(0.001)$ & $0.002(0.001)$ & $0.000(0.002)$ & $0.000(0.001)$ & $0.003(0.003)$ \\
\hline \multicolumn{6}{|l|}{ Household head's age: 13-29 (ref.) } \\
\hline Household head's age: $30-59$ & $-0.008^{* * *}(0.001)$ & $-0.009^{* * * *}(0.002)$ & $-0.002(0.002)$ & $-0.004^{* *}(0.001)$ & $-0.007^{* *}(0.003)$ \\
\hline Household head's age: $60+$ & $-0.015^{* * *}(0.002)$ & $-0.016^{* * *}(0.002)$ & $-0.005^{*}(0.003)$ & $-0.007^{* * *}(0.002)$ & $-0.009^{* *}(0.004)$ \\
\hline $\begin{array}{l}\text { Exposed to media (TV, newspaper, } \\
\text { radio) }\end{array}$ & $-0.021^{* * *}(0.001)$ & $-0.023^{* * *}(0.001)$ & $-0.022^{* * *}(0.002)$ & $-0.019^{* * *}(0.001)$ & $-0.021^{* * *}(0.002)$ \\
\hline Rural household & $-0.005^{* * *}(0.001)$ & $-0.006^{* * *}(0.002)$ & $0.005^{* *}(0.002)$ & $0.004^{* *}(0.002)$ & $-0.001(0.003)$ \\
\hline \multicolumn{6}{|l|}{ Household wealth quintile: Poorest (ref.) } \\
\hline Poorer & $-0.035^{* * *}(0.001)$ & $-0.035^{* * *}(0.001)$ & $-0.023^{* * *}(0.002)$ & $-0.026^{* * *}(0.001)$ & $-0.025^{* * *}(0.003)$ \\
\hline Middle & $-0.065^{* * *}(0.001)$ & $-0.066^{* * *}(0.002)$ & $-0.044^{* * *}(0.002)$ & $-0.047^{* * *}(0.002)$ & $-0.049^{* * * *}(0.003)$ \\
\hline Richer & $-0.091^{* * *}(0.002)$ & $-0.094^{* * *}(0.002)$ & $-0.063^{* * *}(0.002)$ & $-0.065^{* * *}(0.002)$ & $-0.066^{* * *}(0.004)$ \\
\hline Richest & $-0.141^{* * *}(0.002)$ & $-0.149^{* * *}(0.002)$ & $-0.105^{* * *}(0.003)$ & $-0.103^{* * *}(0.002)$ & $-0.105^{* * *}(0.005)$ \\
\hline Country dummies & Yes & Yes & Yes & Yes & Yes \\
\hline Survey year dummies & Yes & Yes & Yes & Yes & Yes \\
\hline$N$ & 919039 & 810280 & 432198 & 652732 & 163172 \\
\hline
\end{tabular}

Notes: The Table reports marginal effects with standard errors in parentheses. ${ }^{* * *},{ }^{* *}$ and ${ }^{*}$ report statistical significance at $1 \%, 5 \%$ and $10 \%$, respectively. The first column reports full sample results; South American countries excluded in column 2; Column 3 reports estimates for African countries; Column 4 excludes India, and Column 5 limits the sample to recent surveys (referred to as DHS-7).

Apart from the main results, other results are consistent with what we would expect in the literature. In particular, from the full sample estimation, we observe better maternal education is associated with lower stunting probability. For example, compared to a 
mother who has no education, a child with a primary educated or at least secondary educated mother has a 2.3 or 8.5 (3.3 or 6.9) percentage points lower probability of being stunted (underweight), respectively. Similarly, mother's experience (age) also helps alleviate child stunting and underweight. Compared to a mother aged 15-19 years, a child whose mother is aged $20-29$ has a 4.9 and 3.3 percentage points lower probability of being stunted and underweight, respectively. Furthermore, a child whose mother is aged 30 or above has a 7.8 and 5.0 percentage points lower probability of being stunted and underweight, respectively. Household head's experience also plays some role in reducing child stunting and underweight, since the associating estimates are negative and significant.

We also observe a significant influence of access to media. Compared to a mother without access to newspaper, radio, or television, a child whose mother has access to media is 1.7 and 2.1 percentage points less likely to be stunted and underweight, respectively (full sample estimation). Finally, compared to a child in the poorest quintile, the probability of being stunted is lower among children from higher wealth quintiles.

\subsection{Robustness Checks}

To test the robustness of our results, we conducted a series of robustness checks. 5.3.1. Sample of most recent-born children

The nutritional outcomes of children may be linked to other factors such as maternal utilisation of antenatal care. However, in the DHS surveys, female respondents were interviewed regarding the antenatal care of only their most recent-born children in the last five years before the survey. In this section, we present the regression results in which we additionally control variables as follows. First, we included a group of variables indicating (i) whether the mother received antenatal care from a medical professional $=1,0$ otherwise; (ii) whether the mother made four antenatal care visits before birth, and (iii) whether the child's birth was at an institution (1) or not (1). Second, another group of dummy variables shows whether a mother's BMI (Body Mass Index, normal is the base case) is underweight (1) or not (0), obese (1) or not (0), not reported (1) or not (0). We also add two other control variables, namely whether the household uses flush toilets (1) or not (0) and piped water (1) or not (0). The sample size for this exercise is around 651,000 observations sourced from 100 surveys in 54 countries.

Table 4. Exposure to Ramadan and child stunting and underweight - sample of most recent-born children

\begin{tabular}{lccccc}
\hline & $(1)$ & $(2)$ & $(3)$ & $(4)$ & $(5)$ \\
& Global & Excl. Americas & Africa & Excl. India & DHS7 \\
\hline Panel A- Outcome variable: Stunting & & & & \\
\hline Muslim & $0.028^{* * *}(0.003)$ & $0.031^{* * *}(0.003)$ & $0.042^{* * *}(0.005)$ & $0.032^{* * * *}(0.004)$ & $0.033^{* * * *}(0.007)$ \\
Exposure & $0.004^{* * *}(0.002)$ & $0.006^{* * *}(0.002)$ & $0.009^{* * *}(0.003)$ & $0.004^{*}(0.002)$ & $0.005(0.004)$ \\
Muslim* Exposure & $-0.008^{* * *}(0.003)$ & $-0.010^{* * *}(0.003)$ & $-0.012^{* * *}(0.004)$ & $-0.007^{*}(0.004)$ & $-0.010(0.007)$ \\
\hline$N$ & 651187 & 571088 & 304654 & 455050 & 113912 \\
\hline Panel A-Outcome variable: Underweight & $0.022^{* * * *}(0.003)$ & $0.024^{* * * *}(0.003)$ & $0.041^{* * * *}(0.004)$ & $0.035^{* * * *}(0.003)$ & $0.032^{* * * *}(0.006)$ \\
\hline Muslim & $0.003(0.002)$ & $0.003^{*}(0.002)$ & $0.003(0.002)$ & $0.002(0.002)$ & $0.002(0.004)$ \\
Exposure & $-0.007^{* * *}(0.003)$ & $-0.008^{* * *}(0.003)$ & $-0.006^{*}(0.004)$ & $-0.006^{* * *}(0.003)$ & $-0.010^{*}(0.005)$ \\
\hline Muslim* Exposure & 647588 & 568450 & 302141 & 451451 & 113688 \\
\hline$N$
\end{tabular}

Note: All models controlled for socioeconomic and demographic characteristics that are controlled in Table 2 and Table 3 and also additionally controlled for antenatal care, mother's BMI, household using flush-toilet and piped water.

The estimation results presented in Table 4 show strong consistency with our findings in the previous section. In other words, Muslim-non-exposed children are more likely to be stunted (Panel A)/underweight (Panel B) than non-Muslim children since the estimates for Muslims is positive and significant. The estimates for the category of children exposed 
to Ramadan (Exposure) is positive but not significant in all the regressions particularly for regressions of underweight; whereas the estimates of the interaction term (Muslims*Exposure) is negative and significant in most of the regressions.

\subsubsection{Controlling for country-level socio-economic indicators}

Table 5 reports estimation results where we additionally control for country-level economic characteristics. Specifically, we included the variables (log) human development index (HDI), (log) GDP per head, and (log) health expenditure per capita (HXPDPCAP) in the year of child's birth, for the full sample and DHS-7 Sample. ${ }^{2}$

Table 5. Exposure to Ramadan fasting and child stunting and underweight - additional controls

\begin{tabular}{|c|c|c|c|c|c|c|}
\hline & (1) & (2) & (3) & (4) & (5) & (6) \\
\hline & full & DHS7 & full & DHS7 & full & DHS7 \\
\hline \multicolumn{7}{|c|}{ Panel A-Outcome variable: Stunting } \\
\hline Muslim & $0.025^{* * *}(0.003)$ & $0.028^{* * *}(0.006)$ & $0.025^{* * *}(0.003)$ & $0.028^{* * *}(0.006)$ & $0.026^{* * *}(0.003)$ & $0.033^{* * *}(0.006)$ \\
\hline Exposure & $0.004^{* *}(0.002)$ & $0.006(0.004)$ & $0.003^{* *}(0.002)$ & $0.006(0.004)$ & $0.004^{* *}(0.002)$ & $0.007^{*}(0.004)$ \\
\hline Muslim* Exposure & $-0.007^{* * * *}(0.003)$ & $-0.008(0.006)$ & $-0.007^{* * *}(0.003)$ & $-0.008(0.006)$ & $-0.008^{* * *}(0.003)$ & $-0.014^{* *}(0.006)$ \\
\hline HDI & $0.056^{*}(0.032)$ & $-0.049(0.067)$ & & & & \\
\hline GDP per head & & & $0.016^{*}(0.009)$ & $0.041(0.028)$ & & \\
\hline HXPDPCAP & & & & & $-0.010^{* * *}(0.003)$ & $-0.013^{* *}(0.006)$ \\
\hline$N$ & 921393 & 163348 & 924077 & 163348 & 911597 & 160584 \\
\hline \multicolumn{7}{|c|}{ Panel B - Outcome variable: Underweight } \\
\hline Muslim & $0.021^{* * *}(0.003)$ & $0.034^{* * *}(0.005)$ & $0.021^{* * *}(0.003)$ & $0.034^{* * *}(0.005)$ & $0.021^{* * *}(0.003)$ & $0.035^{* * *}(0.005)$ \\
\hline Exposure & $0.002(0.001)$ & $0.001(0.003)$ & $0.002(0.001)$ & $0.001(0.003)$ & $0.002(0.001)$ & $0.001(0.003)$ \\
\hline Muslim* Exposure & $-0.005^{* *}(0.002)$ & $-0.011^{* *}(0.005)$ & $-0.005^{* *}(0.002)$ & $-0.011^{* *}(0.005)$ & $-0.006^{* *}(0.002)$ & $-0.012^{* *}(0.005)$ \\
\hline HDI & $-0.007(0.028)$ & $-0.051(0.054)$ & & & & \\
\hline GDP per head & & & $-0.011(0.008)$ & $-0.103^{* * *}(0.022)$ & & \\
\hline HXPDPCAP & & & & & $-0.003(0.002)$ & $-0.004(0.004)$ \\
\hline$N$ & 916234 & 163051 & 918918 & 163051 & 906439 & 160288 \\
\hline
\end{tabular}

Notes: All models include controls for socioeconomic and demographic characteristics as in Table 2 and Table 3.

The results (Panel A for stunting and Panel B for underweight) show that health expenditure is associated with stunting while higher GDP per capita is associated with lower underweight prevalence. Apart from that, results for our main variables of interest in the full sample are similar to baseline estimates presented in Tables 2 and 3. Overall, the results suggest that Muslim children are more likely to be stunted/underweight, and in-utero exposure to Ramadan fasting has no negative influence on Muslim children.

\subsubsection{Sample of Muslim population}

In this section, we report results considering only the sample of Muslim children. Using equation (1) we directly estimate the relative difference in probability of being stunted or underweight for children with in-utero exposure to Ramadan fasting month, compared to those who were not. The results presented in Table 6 (Panel A) show that the

2 HDI is sourced from UNDP (http://hdr.undp.org/en/content/download-data); GDP per capita is PPP (2017 constant international \$), and health expenditure per capita is domestic general government health expenditure (PPP current international \$) are sourced from World Development Indicators database (The World Bank). 
estimates for the variable of interest are negative, but not statistically significant. Whereas results in Panel B show that the estimates for the variable of interest are negative and significant in all regression models, suggesting that exposed children are roughly 0.4 percentage points (columns 1,2, and 3) to 0.9 percentage points less likely to be underweight than non-exposure counterparts. Again these results emphasise that exposure to Ramadan fasting month doesn't make a significant difference in child nutrition net of other socio-economic factors.

Table 6. Exposure to Ramadan fasting period and child stunting and underweight - sample of Muslim population

\begin{tabular}{lcccc}
\hline & $(1)$ & $(2)$ & $(3)$ & $(4)$ \\
& full & Africa & Excl. India & DHS7 \\
\hline $\begin{array}{l}\text { Panel A-Outcome variable: Stunting } \\
\text { Exposure }\end{array}$ & $-0.004(0.002)$ & $-0.002(0.002)$ & $-0.003(0.003)$ & $-0.005(0.004)$ \\
\hline$N$ & 299294 & 257340 & 193297 & 72904 \\
\hline Panel B - Outcome variable: Underweight & & & $-0.009^{* * *}(0.003)$ \\
\hline Exposure & $-0.004^{* *}(0.002)$ & $-0.004^{*}(0.002)$ & $-0.004^{*}(0.002)$ & 72836 \\
\hline$N$ & 299190 & 193213 & 257236 & \\
\hline
\end{tabular}

Note: All models controlled for socioeconomic and demographic characteristics are controlled in Table 2 and Table 3.

\subsubsection{Heterogeneity of the exposure effects.}

Previous research, for example, Chaudhry and Mir [14] have shown that the potential impacts on child health due to in-utero exposure Ramadan fasting month will likely depend on the timing of the exposure. Before that, Awwad et al. [26] based on their prospective study revealed that gestational age may not influence the relationship between Ramadan fasting and maternal health. Considering these contradicting findings from local level micro studies, we assessed whether the timing of Ramadan exposure during pregnancy matters for health outcomes using a relatively large sample across geographies. Below we provide empirical results in which we consider the sample of the Muslim population and classify children by the timing of in utero exposure.

\subsubsection{Exposure by trimesters}

Based on a full sample of the Muslim population in our dataset, we create binary variables indicating whether a child is exposed in-utero to the Ramadan month during the first trimester (1) or not (0); or in between first and second trimesters (1) or not (0); or second trimester $(1)$ or not $(0)$, in between second and third trimesters $(1)$ or not $(0)$, or third trimester (1) or not (0); the base case is non-exposure (A child is considered to have exposure in utero during a trimester if this trimester overlaps at least 7 days with the Ramadan month). We then execute an estimation introducing these new variables. We report the marginal effects in Table 7.

In the case of stunting, the general results in Panel A show that exposure during the first or second trimester may be positively associated with stunting while exposure from the last month of the second trimester and third trimester are negatively related (column 1). These results are consistent in the sample with American countries excluded (column 2), or sample of African countries only (column 3), or sample with India excluded (column 4). In column 5, we limited the sample to the most recent surveys where information on the date of birth of the child is available, thus the pregnancy period is more precisely imputed. The results show that exposure during the first trimester, or partly first and partly 
second trimesters, are negatively associated with child growth. While exposure in the second or third trimester is not negatively associated with child growth. Results regarding children underweight presented in Panel B show a similar pattern of the effects.

Table 7. Exposure to Ramadan fasting period and child stunting and underweight by trimesters.

\begin{tabular}{|c|c|c|c|c|c|}
\hline & (1) & (2) & (3) & (4) & (5) \\
\hline Variable & Global & Excl. America & Africa & Excl. India & DHS7 \\
\hline \multicolumn{6}{|l|}{ Panel A - Outcome variable: Stunting } \\
\hline Exposed in trimester 1 & $0.003(0.003)$ & $0.003(0.003)$ & $0.007^{* *}(0.003)$ & $0.006^{* *}(0.003)$ & $0.013^{* * *}(0.004)$ \\
\hline $\begin{array}{l}\text { Exposed in between } 1 \text { st and } 2 \text { nd } \\
\text { trimesters }\end{array}$ & $0.003(0.004)$ & $0.003(0.004)$ & $0.006(0.005)$ & $0.006(0.004)$ & $0.022^{* * * *}(0.006)$ \\
\hline Exposed in trimester 2 & $0.001(0.003)$ & $0.001(0.003)$ & $0.002(0.003)$ & $0.002(0.003)$ & $-0.024^{* * *}(0.004)$ \\
\hline $\begin{array}{l}\text { Exposed in between 2nd and 3rd } \\
\text { trimesters }\end{array}$ & $-0.010^{* * *}(0.004)$ & $-0.010^{* *}(0.004)$ & $-0.015^{* * *}(0.005)$ & $-0.006(0.005)$ & $-0.015^{*}(0.008)$ \\
\hline Exposed in trimester 3 & $-0.014^{* * *}(0.003)$ & $-0.014^{* * *}(0.003)$ & $-0.016^{* * *}(0.003)$ & $-0.012^{* * * *}(0.003)$ & $-0.014^{* * *}(0.005)$ \\
\hline$N$ & 299294 & 299226 & 193229 & 257340 & 72904 \\
\hline \multicolumn{6}{|l|}{ Panel B - Outcome variable: Underweight } \\
\hline Exposed in trimester 1 & $-0.002(0.002)$ & $-0.002(0.002)$ & $-0.000(0.003)$ & $-0.001(0.002)$ & $0.007^{* *}(0.004)$ \\
\hline $\begin{array}{l}\text { Exposed in between 1st and } 2 \text { nd } \\
\text { trimesters }\end{array}$ & $-0.001(0.004)$ & $-0.001(0.004)$ & $-0.003(0.005)$ & $-0.002(0.004)$ & $-0.008(0.006)$ \\
\hline Exposed in trimester 2 & $-0.002(0.002)$ & $-0.002(0.002)$ & $-0.002(0.003)$ & $-0.002(0.003)$ & $-0.010^{* *}(0.004)$ \\
\hline $\begin{array}{l}\text { Exposed in between 2nd and } 3 \mathrm{rd} \\
\text { trimester }\end{array}$ & $-0.008^{* *}(0.004)$ & $-0.008^{* *}(0.004)$ & $-0.013^{* * *}(0.005)$ & $-0.008^{* *}(0.004)$ & $-0.005(0.007)$ \\
\hline Exposed in trimester 3 & $-0.008^{* * *}(0.002)$ & $-0.008^{* * *}(0.002)$ & $-0.009^{* * *}(0.003)$ & $-0.008^{* * *}(0.002)$ & $-0.014^{* * *}(0.004)$ \\
\hline$N$ & 299190 & 299190 & 193213 & 257236 & 72836 \\
\hline
\end{tabular}

Note: All models controlled for socioeconomic and demographic characteristics are controlled in Table 2 and Table 3.

\subsubsection{Exposure by months}

Existing literature from a country-specific perspective suggests that in-utero exposure to Ramadan fasting in the early stages of gestation exerts stronger negative effects on the health outcomes of children [14]. Given the overall findings presented until this point, we design another sample of Muslim children only within recent surveys where the information of the date and month of birth of the child are available. Using this sample, we estimate the heterogeneous effects of exposure by month of gestation to the Ramadan month.

Consistent with the literature, our results in Table 8 show that exposure to Ramadan up to 3 rd month of gestation is negatively associated with child stunting. From column 1 , we observe that compared to a non-exposed child, a child would be 2.0, 2.3, 1.5, and 2.1 percentage points more likely to be stunted if his/her mother was exposed to Ramadan month during conception, first month, second month, or third month of pregnancy, respectively. The results when we control for the level of HDI (column 3), GDP per capita (column 4), or health expenditure per capita (column 5) are more or less the same. When the sample is limited to most recent-born children (column 2), the influence of exposure in the second and third months is less clear. From months 4 to 6 of the gestation period, the pattern of influence of exposure to Ramadan fasting reverses, and the results are consistent in all 5 specifications. Compared to non-exposure children, the strongest positive effect is found for children of 4 th month in-utero exposure: 2.0 to 2.2 percentage points less 
likely to be stunted; exposure in 5th and 6th-month associates with around 1.3-1.4 percentage points lower probability of being stunted. Lastly, exposure during the 8th or 9th (born in the month of Ramadan) month of pregnancy seems not to affect the probability of being stunted.

Table 8. Exposure to Ramadan fasting period and child stunting by month of exposure.

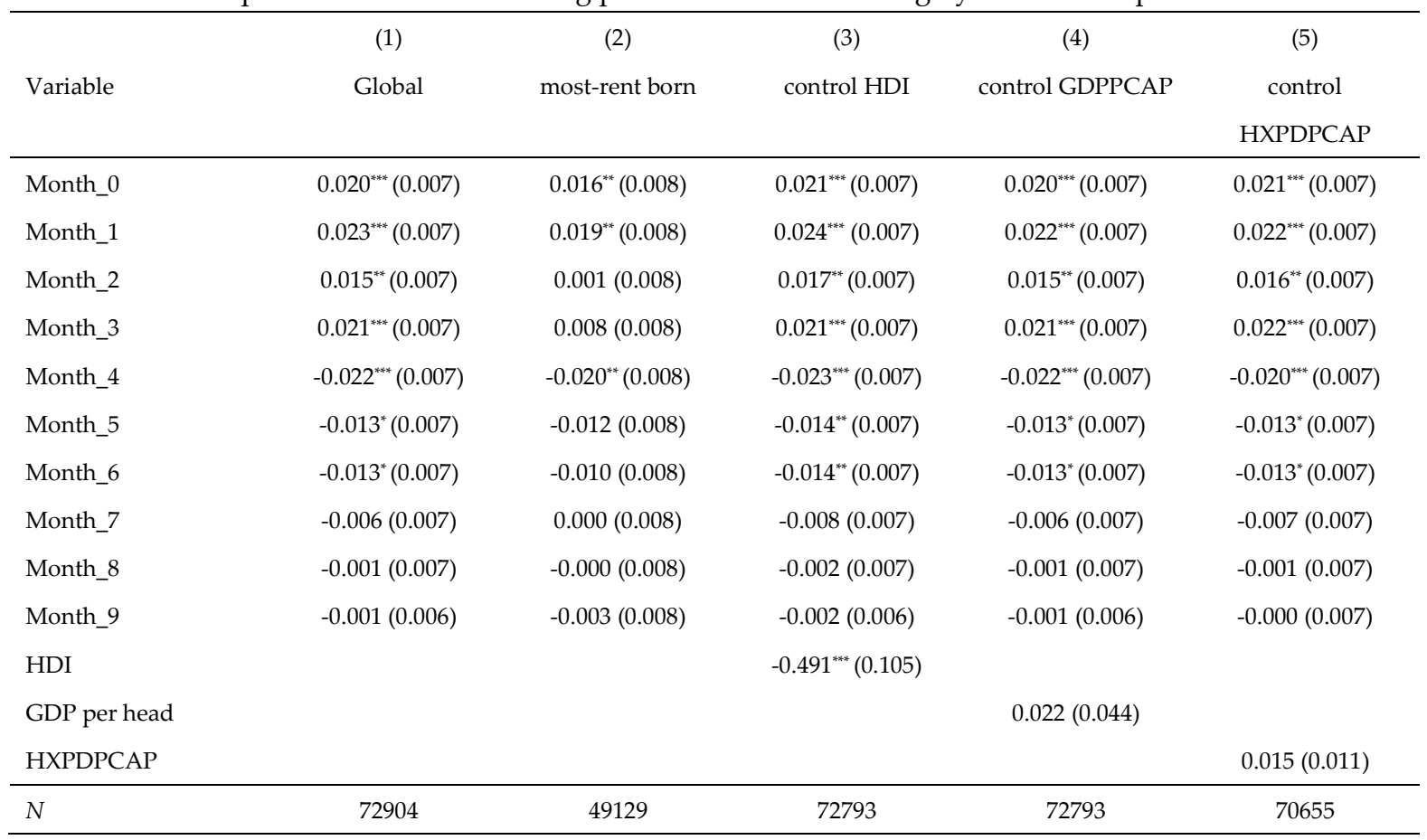

Notes: In Table 4.2 and 4.3, Month_0 is a binary variable indicating whether a child was exposed to Ramadan fasting during conception (1) or not (0). Month_j indicates whether a child was exposed during the month $j$ of pregnancy period (1) or not (0), and Month_9 indicates a child was born in the month of Ramadan (1) or not (0). All models controlled for socioeconomic and demographic characteristics are controlled in Table 2 and Table 3.

In the case of underweight, from Table 9 we observe a negative association between Ramadan exposures in the first three months of pregnancy since the estimates for the variable of interest are positive but not significant. Nevertheless, the strongest negative correlation is found due to exposure during the conception period (roughly 1 percentage point higher probability of being underweight if the imputed starting day of conception fell in the month of Ramadan). From Table 9, estimates for exposure in months 4 to 9 are negative and statistically significant which suggests that the probability of being underweight is lower for exposed children than non-exposed children. The results still hold in a sample of most recent-born children (column 2), and when we control for country-level of macro-economic variables (such as Human Development Index (HDI), GDP per capita, or health expenditure per capita (columns 3-5). From column 1 we observe that the probability of children being underweight is $1.7,1.1,1.01,7,1.4$, and 1.6 percentage points lower if their mother were exposed to the Ramadan fasting month during the period 4 th to 9 th month of gestation, respectively. 
Table 9. Exposure to Ramadan fasting period and child underweight by month of exposure.

\begin{tabular}{|c|c|c|c|c|c|}
\hline Variable & $\begin{array}{c}(1) \\
\text { Global }\end{array}$ & $\begin{array}{c}(2) \\
\text { most-rent born }\end{array}$ & $\begin{array}{c}\text { (3) } \\
\text { control HDI }\end{array}$ & $\begin{array}{c}(4) \\
\text { control GDP }\end{array}$ & $\begin{array}{c}(5) \\
\text { control } \\
\text { HXPDPCAP }\end{array}$ \\
\hline Month_0 & $0.009(0.006)$ & $0.012^{*}(0.007)$ & $0.010^{*}(0.006)$ & $0.010^{*}(0.006)$ & $0.008(0.006)$ \\
\hline Month_1 & $0.001(0.006)$ & $0.002(0.007)$ & $0.004(0.006)$ & $0.004(0.006)$ & $-0.001(0.006)$ \\
\hline Month_2 & $0.005(0.006)$ & $-0.002(0.007)$ & $0.008(0.006)$ & $0.007(0.006)$ & $0.003(0.006)$ \\
\hline Month_3 & $-0.005(0.006)$ & $-0.013^{*}(0.007)$ & $-0.004(0.006)$ & $-0.005(0.006)$ & $-0.006(0.006)$ \\
\hline Month_4 & $-0.017^{4 *+*}(0.006)$ & $-0.011(0.007)$ & $-0.019^{* * * *}(0.006)$ & $-0.019^{* * * * *}(0.006)$ & $-0.017^{* * * *}(0.006)$ \\
\hline Month_5 & $-0.011^{*}(0.006)$ & $-0.010(0.007)$ & $-0.012^{* *}(0.006)$ & $-0.012^{* *}(0.006)$ & $-0.011^{*}(0.006)$ \\
\hline Month_6 & $-0.010^{*}(0.006)$ & $-0.007(0.007)$ & $-0.011^{*}(0.006)$ & $-0.011^{*}(0.006)$ & $-0.010^{*}(0.006)$ \\
\hline Month_7 & $-0.017^{* * *}(0.006)$ & $-0.014^{* *}(0.007)$ & $-0.018^{* * *}(0.006)$ & $-0.018^{* * *}(0.006)$ & $-0.018^{* * *}(0.006)$ \\
\hline Month_8 & $-0.014^{* *}(0.006)$ & $-0.012^{*}(0.007)$ & $-0.016^{* * *}(0.006)$ & $-0.015^{* *}(0.006)$ & $-0.016^{* *}(0.006)$ \\
\hline Month_9 & $-0.016^{* * *}(0.006)$ & $-0.016^{* *}(0.007)$ & $-0.017^{* * *}(0.006)$ & $-0.017^{* * *}(0.006)$ & $-0.017^{* * *}(0.006)$ \\
\hline HDI & & & $-0.728^{* * *}(0.090)$ & & \\
\hline GDP per head & & & & $-0.235^{* * * *}(0.038)$ & \\
\hline HXPDPCAP & & & & & $0.042^{* * *}(0.009)$ \\
\hline$N$ & 72836 & 49070 & 72725 & 72725 & 70587 \\
\hline
\end{tabular}

Notes: All models controlled for socioeconomic and demographic characteristics that are controlled in Table 2 and Table 3.

\section{Discussion and Conclusion}

Our analysis using an intent-to-treat framework comparing nutrition outcomes among children who were exposed to the Ramadan fasting period any time in-utero to those who were not exposed finds no negative influence of exposure to the Ramadan fasting period on child nutritional outcomes. Thus, our findings fail to support the hypothesis that exposure to the Ramadan fasting period is negatively associated with child nutritional outcomes. These findings are robust to sub-samples by religion, regions, and months after controlling for several socioeconomic, demographic, and maternal health care variables. The only exception is exposure during the early months of pregnancy has a slightly negative influence on child linear growth but not on the underweight. Our results using data from a sample of over 56 countries are in contrast to previous research using specific country contexts $[7,8,9,10,11,21]$. However, our results are in line with a majority of the studies $[14,15,16,17,18]$, and conclusions of systematic reviews of global literature by Oosterwijk et al. [1] and Glazier et al. [19]. Nonetheless, we failed to link changes in dietary practices during Ramadan to child nutrition. The information on dietary behaviours of respondents was not available in DHS, making it difficult to classify with complete certainty if and how frequently or strictly fasting was undertaken by pregnant women, and account for the change in quantity and nutritional diversity of their food consumption during the fasting month.

A hypothesis espoused from previous micro case studies which documented dietary and lifestyle practices during Ramadan fasting may help in explaining our results. Ramadan encourages a healthy lifestyle and Muslim people tend to have a better and more diverse diet during the Ramadan fasting month, even when eating and drinking happens only before sunrise and after sunset [3,21,34]. Usually, households tend to spend more financial resources during festive seasons. A more recent report points out that even though Ramadan is a fasting month, food intake during the time of Iftar to Suhoor outdoes the usual eating pattern. Specifically, consumption of fruits, highly nutrient nuts, dairy products, and meat increase significantly during Ramadan. While the reduced working 
hours during the Ramadan fasting month also lessens overall energy requirements. The report further notes "not only food bills increase by $50-100 \%$ during Ramadan, but it is reported that $83 \%$ of families change their food consumption habits during Ramadan. It is estimated that food consumption in Ramadan accounts for $15 \%$ of annual expenditure on food" [33].

The evidence from Indonesia also supports this. Muslim wage earners would receive a bonus (known as Tunjangan Hari Raya, or THR) from their employers before the Ramadan month. This bonus can be used to finance better food consumption during the month. The tradition of Zakat or giving charity generates more financial resources for marginalised Muslim people, hence temporarily during the Ramadan month the distribution of food consumption improves in favour of the poor and less well-off households. This in turn leads to a better diet generally among the population during the Ramadan months. Extending this hypothesis further, Kunto and Mandemarkers [5] found that exposure to Ramadan fasting exerted positive effects on stature for less-religious Muslim children aged 10-14, and negative effects for non-Muslims aged 0-4 in Indonesia. The authors then speculate on the possible impact of THR and Zakat as an explanation for their findings. While the higher demand shock would increase price levels and harm the nonMuslim community.

Previous research that shows Muslim advantage in child nutrition and child survival in South Asia attribute it to better hand washing and hygienic practices among Muslims especially before prayers [35]. While it is well known that the number of times Muslims perform prayers during the holy month of Ramadan is higher than normal days, they also keep their surroundings relatively more clean and hygienic during Ramadan compared to normal days. This may enable relatively healthier maternal lifestyles and hygienic practices during Ramadan. This in turn may potentially help achieve better pregnancy outcomes and child health.

Author Contributions: Conceptualization, Anu Ramohan and Srinivas Goli.; methodology, Anu Rammohan and Srinivas Goli; software, Hoi Chu; validation, Anu Rammoha and Srinivas Goli; formal analysis, Hoi Chu; investigation, Hoi Chu and Srinivas Goli; resources, Anu Ramoohan; data curation, Hoi Chu; writing - original draft preparation, Hoi Chu; writing-review and editing, Anu Rammohan and Srinivas Goli.; visualization, Hoi Chu and Srinivas Goli; supervision, Anu Rammohan; project administration, Anu Rammohan. All authors have read and agreed to the published version of the manuscript.

Funding: This research received no external funding.

Data Availability Statement: The main datasets used in this study is available and can be download directly from the website https://dhsprogram.com/.

Conflicts of Interest: The authors declare no conflict of interest.

\section{References}

1. Oosterwijk, V.N.L.; Molenaar, J.M.; van Bilsen, L.A.; Kiefte-de Jong, J. C. Ramadan fasting during pregnancy and health outcomes in offspring: A systematic review. Nutrient 2021, 13(3450).

2. Mubeen, S.M.; Mansoor, S.; Hussain, A.; Qadir, S. Perceptions and practices of fasting in Ramadan during pregnancy in Pakistan. Iranian journal of nursing and midwifery research 2012, 17(7); 467-471.

3. Seiermann A.U.; Al-Mufti, H.; Waid, J.L.; Wendt, A.S.; Sobhan, S.; Gabrysch S. Women's fasting habits and dietary diversity during Ramadan in rural Bangladesh. Matern Child Nutr 2021, 17(3):e13135.

4. Baynouna Al Ketbi, L.M.; Niglekerke, N.J.; Zein Al Deen, S.M.; Mirghani, H. Diet restriction in Ramadan and the effect of fasting on glucose levels in pregnancy. BMC Res Notes 2014, 7(392).

5. Kunto, Y.S.; Mandemakers, J.J. The effects of prenatal exposure to Ramadan on stature during childhood and adolescence: Evidence from the Indonesian Family Life Survey. Econ Hum Biol 2019, (33): 29-39.

6. Van Ewijk, R.J.; Painter, R.C.; Roseboom, T.J. Associations of prenatal exposure to Ramadan with small stature and thinness in adulthood: results from a large Indonesian population-based study. American journal of epidemiology 2013, 177(8): 729-736.

7. Majid, M.F. The persistent effects of in utero nutrition shocks over the life cycle: Evidence from Ramadan fasting. Journal of Development Economics 2015, (117):48-57. 
8. Almond, D.; B. Mazumder, B. Health Capital and the Prenatal Environment: The Effect of Ramadan Observance during Pregnancy. American Economic Journal: Applied Economics 2011, (3): 56-85.

9. Barker, D. J. The fetal and infant origins of adult disease. BMJ: British Medical Journal 1990, 301(6761): 1111.

10. Almond, D.; Currie, J. Killing me softly: The fetal origins hypothesis. Journal of Economic Perspectives 2011, 25(3): 153-172.

11. Wu, G.; Bazer, F.W.; Cudd, T.A.; Meininger, C.J.; Spencer, T.E. Maternal nutrition and fetal development. The Journal of nutrition 2004, 134(9): 2169-2172.

12. Malhotra, A.; Scott, P.H.; Scott, J.; Gee, H.; Wharton, B.A. Metabolic changes in Asian Muslim pregnant mothers observing the Ramadan fast in Britain. British Journal of Nutrition 1989, (61): 663-672.

13. Prentice, A.M.; Prentice, A.; Lamb, W.H.; Lunn, P.G.; Austin, S. Metabolic consequences of fasting during Ramadan in pregnant and lactating women, Human nutrition. Clinical nutrition 1983, 37(4): 283-294.

14. Chaudhry, T.T.; Mir, A. The impact of prenatal exposure to Ramadan on child anthropometric outcomes in Pakistan. Maternal and Child Health Journal 2021, 25:1136-1146.

15. Kavehmanesh, Z.; Abolghasemi, H. Maternal Ramadan fasting and neonatal health. Journal of Perinatology 2004, 24(12): 748-750.

16. Petherick, E.S.; Tuffnell, D.; Wright, J. Experiences and outcomes of maternal Ramadan fasting during pregnancy: results from a sub-cohort of the Born in Bradford birth cohort study. BMC pregnancy and childbirth 2014, 14(1): 1-9.

17. Savitri, A.I.; Painter, R.C.; Lindeboom, M.; Roseboom, T.J.; Van Ewijk, R.J. Ramadan exposure and birth outcomes: a populationbased study from the Netherlands. Journal of developmental origins of health and disease 2020, 11(6): 664-671.

18. Moradi, M. The effect of Ramadan fasting on fetal growth and Doppler indices of pregnancy. J Res Med Sci 2011, (16(2): 165-169.

19. Ziaee, V.; Kihanidoost, Z.; Younesian, M.; Akhavirad, M. B.; Bateni, F.; Kazemianfar, Z.; Hantoushzadeh, S. The effect of Ramadan fasting on the outcome of pregnancy. Iranian Journal of pediatrics 2010, 20(2): 181-186.

20. Glazier, J.D.; Hayes, D.J.L.; Hussain, S. et al. The effect of Ramadan fasting during pregnancy on perinatal outcomes: a systematic review and meta-analysis. BMC Pregnancy Childbirth 2018, 18(421).

21. Ali, Z.; Abizari, A.R. Ramadan fasting alters food patterns, dietary diversity, and body weight among Ghanaian adolescents. Nutr J 2018, 17(75).

22. Van Ewijk, R. Long-term health effects on the next generation of Ramadan fasting during pregnancy. Journal of health economics 2011, 30(6): 1246-1260.

23. Brace, R.A. Physiology of Amniotic Fluid Volume Regulation. Clin. Obstet. Gynecol 1997, 40: 280-289.

24. Almond, D.; Mazumder, B.; Van Ewijk, R. In utero Ramadan exposure and children's academic performance. The Economic Journal 2015, 125(589): 1501-1533.

25. Schoeps, A.; van Ewijk, R.; Kynast-Wolf, G.; Nebié, E.; Zabré, P.; Sié, A.; Gabrysch S. Ramadan exposure in utero and child mortality in Burkina Faso: analysis of a population-based cohort including 41,025 children. American journal of epidemiology 2018, 187(10): 2085-2092.

26. Awwad, J.; Usta, I.M.; Succar, J.; Musallam, K.M.; Ghazeeri, G.; Nassar, A.H. The effect of maternal fasting during Ramadan on preterm delivery: a prospective cohort stud. BJOG: An International Journal of Obstetrics and Gynaecology 2012, 119(11): $1379-1386$.

27. Nikoo M.K.; Shadman, Z.; Larijani, B. Ramadan Fasting, Pregnancy, and Lactation. Iran. South Med 2014, 17: 99-106.

28. Savitri, A.I., Amelia, D.; Painter, R.C.; Baharuddin, M.; Roseboom, T.J.; Grobbee, D.E.; Uiterwaal, C.S. Ramadan during pregnancy and birth weight of newborns. Journal of Nutritional Science 2018, 7.

29. WHO Multicentre Growth Reference Study Group. Enrolment and baseline characteristics in the WHO Multicentre Growth Reference Study, Acta Paediatrica Suppl 2006, 450: 7/15.

30. Balla, S.; Goli, S.; Vedantam, S.; Rammohan, A. Progress in child stunting across the world from 1990 to 2015: testing the global convergence hypothesis. Public Health Nutrition 2021, 24(17): 5598-2607.

31. Martorell, R.; Young, M.F. Patterns of stunting and wasting: potential explanatory factors. Advances in nutrition 2012, 3(2): 227233.

32. Raiten, D.J.; Bremer, A.A. Exploring the Nutritional Ecology of Stunting: New Approaches to an Old Problem. Nutrients 2020, 12(2): 371 .

33. Yousef, A. The economic impact of Ramadan on the food sector: Time of less productivity or business opportunity? 2021, available online https://www.hlb.global/the-economic-impact-of-ramadan-on-the-food-sector/.

34. Al-Hourani, H.M.; Atoum, M.F. Body composition, nutrient intake, and physical activity patterns in young women during Ramadan. Singapore medical journal 2007, 48(10): 906-10.

35. Brainerd, E.; Menon, M. Religion and health in early childhood: Evidence from South Asia. Population and Development Review 2015, 41(3), 439-463. 